\title{
Comparison of methods for estimating the carcass stiffness of agricultural tyres on hard surfaces
}

by Misiewicz, P.A., Richards, T.E., Blackburn, K. and Godwin, R.A.

Copyright, Publisher and Additional Information: This is the author accepted manuscript. The final published version (version of record) is available online via Elsevier Please refer to any applicable terms of use of the publisher.

DOI: 10.1016/j.biosystemseng.2016.03.001

Harper Adams

University 


\title{
1 Comparison of methods for estimating the carcass
}

\author{
P. A. Misiewicz ${ }^{a, k}$, T. E. Richards ${ }^{b}$, K. Blackburn ${ }^{b}$ and R. J. Godwin ${ }^{a}$
}

5

aHarper Adams University, Newport, Shropshire, TF10 8NB, UK

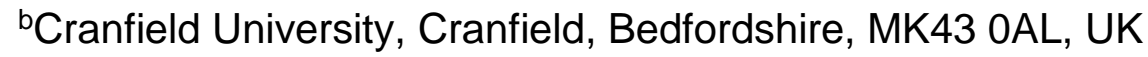

*e-mail of corresponding author: p.misiewicz@iagre.biz

\section{Abstract}

Loading soil via pneumatic tyres is a major cause of compaction of agricultural soils, which causes damage to the soil-water-air-plant system. The loads applied to the soil and the resulting pressure influences the degree of soil compaction. This study was conducted to determine an effective method to measure the pressure distribution under a selection of pneumatic agricultural tyres. This was conducted initially on a non-deformable surface; a later study will consider pressures within the subsoil. From this the tyre carcass stiffness was determined and methods to predict carcass stiffness were evaluated. Tyre carcass stiffness is defined as an equivalent pressure resulting from the stiffness of the tyre carcass. In order to estimate the carcass stiffness of tyres a number of approaches were considered including: (i) footprint area, (ii) tyre load - deflection, (iii) pressure mapping and (iv) tyre manufacturer's specification methods. Carcass stiffness values obtained from the footprint area method gave results significantly lower $(30-40 \%)$ than those obtained using the pressure mapping system. The method based on the tyre load - deflection characteristics was found to give a better estimation of the tyre carcass stiffness of the smooth rather than the treaded tyre. The technique of using the tyre manufacturer's specification data, where the estimation of the tyre carcass stiffness was calculated using the theoretical load that the tyre could support at zero inflation pressure, produced estimates that were within $\pm 20 \%$ of the mean carcass stiffness determined using the pressure mapping system.

Keywords: tyre carcass stiffness; contact pressure; pressure mapping; soil - tyre interactions. 


\section{Nomenclature}

$36 \quad c_{1} \quad$ tyre carcass stiffness coefficient

$37 \quad P_{C} \quad$ tyre contact pressure, $\mathrm{Pa}$

$38 \quad P_{C S} \quad$ tyre carcass stiffness pressure, $\mathrm{Pa}$

$39 \quad P_{i} \quad$ tyre inflation pressure, $\mathrm{Pa}$

$40 \quad R^{2} \quad$ coefficient of determination

\section{Introduction}

43 The steady increase in the power and weight of agricultural machines over recent

44 decades (Horn et al., 2006) has caused a negative effect on soil structure, workability, crop development and yield by increasing soil compaction (Chamen, 2011). The heavier and more powerful machines, which have been introduced to improve mechanisation efficiency, have succeeded in reducing costs and improving the timeliness of crop management operations, however, their use may have a negative effect on soils which are susceptible to compaction (Koch et al., 2008).

The application of load on the soil surface (i.e. on the soil - tyre contact area) transfers stresses through the soil profile which may result in soil compaction if the stress experienced at a given depth exceeds the soil strength. The tyre - soil contact pressure largely determines the degree of surface compaction (Söhne, 1958) and the upper boundary condition for soil stress propagation through the profile depth (Keller and Lamande, 2010). Therefore, the assessment of the contact pressure is of great importance because of its effect on soil compaction. Tyre contact pressure is considered to be an indicator of the potential to cause compaction in the upper layers of the soil (VandenBerg and Gill, 1962; Plackett 1984).

Bekker (1956) noted that the pressure distribution in the case of an ideally elastic

63 tyre on a rigid surface would be uniform and equal to the inflation pressure.

64 However, the presence of tyre treads and carcass stiffness changes this relationship.

65 He presented a simple contact pressure distribution for a solid rubber tyre and a 66 pneumatic tyre, both on a hard surface. The contact pressure distribution for a tyre

67 is not constant; it varies depending on the stiffness of the tyre. 
69 Soil compaction can result from high contact pressure, low soil strength, or both 70 (Soane et al., 1981). Chancellor (1976), Plackett (1983 and 1986) and Plackett et al. (1987) investigated the factors causing soil compaction and agreed that the major factor was high soil contact pressure. They looked at the contact pressure resulting from agricultural tyres and then related it to the inflation pressure and carcass stiffness. They indicated that mean contact pressure $\left(P_{C}\right)$ could be defined as inflation pressure $\left(P_{i}\right)$ plus carcass stiffness pressure $\left(P_{C S}\right)$ :

$$
P_{C}=P_{i}+P_{C S}
$$

For the purpose of this work, following Bekker (1956), Chancellor (1976) and Plackett (1983), the term tyre carcass stiffness is considered to be an equivalent pressure arising from the stiffness of the tyre carcass. Chancellor (1976) considered different factors affecting the relationship between soil pressure and compactability including soil moisture content, texture, vibration, repeated loading, loading speed and loading period. Unfortunately no experimental results could be found to support his analysis and conclusions.

The studies by Plackett (1983) provided data for agricultural tyres showing the variation in contact area for increasing loads up to the maximum rated load for the minimum recommended inflation pressure. His research indicated a simple method of measuring hard surface ground contact area and computing the mean contact pressure by dividing the load by the contact area. He suggested that the tyre carcass stiffness contributes to the contact pressure and assumed that this contribution is constant over the tyre deflection range studied. The tyre carcass stiffness was predicted by examining the load - deflection curves for a given tyre.

In their discussion on pneumatic tyre - soil interactions, Karafiath and Nowatzki (1978) offered a different relationship between the average contact pressure and inflation pressure, presented by Eq. 2, which suggests that the effect of inflation pressure on the contact pressure is affected by a carcass stiffness coefficient $\left(c_{1}\right)$.

$$
P_{C}=c_{1} P_{i}+P_{C S}
$$


100 At present, there is no agreed standard method for determining the contact area or contact pressure of loaded agricultural tyres. With the general increase in the size and power of machines and a better understanding of the factors affecting plant growth, there is a need for further detailed research on soil contact pressure caused by vehicular traffic to aid tyre selection.

This manuscript describes an investigation of contact pressures resulting from loaded agricultural tyres on hard surfaces, which should enable improved tyre selection for better soil management. A study on the effect of tyres and rubber tracks at high axle loads on soil compaction by Ansorge and Godwin (2007) emphasised the importance of contact pressure distribution with respect to changes in soil compaction. They argued that a uniform pressure distribution is essential to minimise soil compaction, which was supported by the results of Schjonning et al.

113 (2008).

As tyre contact pressure is a combination of tyre inflation pressure and carcass stiffness (Chancellor, 1976; Plackett, 1983), the objective of this article is to:-

i. Determine an effective method to measure the contact pressure distribution from pneumatic agricultural tyres on a hard surface,

\section{Materials and Methods}

In order to determine the carcass stiffness of a tyre on hard surfaces, a number of approaches were considered including:

i. The footprint area method, using an ink marker, to estimate the size of the contact patch and hence the mean contact pressure,

ii. The tyre load - deflection method,

iii. The pressure mapping method to measure the pressure distribution using a commercial pressure mapping system,

iv. Tyre manufacturer's specification methods (two variants).

133 The technique using the footprint area, proposed by Plackett (1983), is based on the 
assumption that tyre carcass stiffness is a constant value for a tyre (Bekker, 1956 and Chancellor, 1976) and is calculated as the difference between the mean contact pressure and tyre inflation pressure. Tyre contact area was found by loading tyres, coated in black ink, onto a white card placed on a steel plate. The mean and maximum contact pressures under a tyre were calculated by dividing tyre load by the projected area and tread contact area, respectively. The projected contact area was obtained by loading and rotating a tyre a number of times, while the tread contact area was given by a single ink print.

Plackett (1983) also predicted the contribution of the tyre carcass stiffness by examining the load - deflection characteristic of a tyre at a range of inflation pressures from which the tyre sidewall stiffness could be estimated. Using this method, the maximum vertical deflection of tyres loaded onto a steel plate was measured using two drawstring potentiometers, one on each side of the tyre, which were connected between the axle and the steel plate. The relationships were then plotted as load vs. deflection (Fig. 1). As the tyre inflation pressure decreases, the slope of the load - deflection curve also decreases. If a tyre has zero carcass stiffness, then the slope of the load - deflection relationship would be zero at zero inflation pressure, as the carcass would not support any load. Therefore, plotting the slope of the load - deflection curve against inflation pressure, as shown in Fig. 2, and extrapolating the relationship to the inflation pressure axis gives an estimation of the carcass strength at zero inflation pressure (abscissa) and the pressure at which the carcass strength is zero (ordinate). Plackett (1983) suggested that the negative value of the inflation pressure at zero slope (load - deflection) is an indication of the tyre carcass stiffness. determining carcass stiffness. The mean and maximum contact pressures are determined using a pressure mapping system and mean and maximum tyre carcass stiffness are calculated as the differences between the mean and maximum contact pressures and tyre inflation pressure, respectively. The use of a pressure mapping system (Tekscan System, I-Scan version, Tekscan Inc., South Boston, Mass., USA) allows the real-time pressure distribution to be viewed and recorded across the contact patch using a sensor array. The system had not been previously used in 
contact pressure experiments with agricultural tyres and for its use here required a bespoke calibration to be developed. This employed, both, an individual and multipoint calibration of each sensing element and the rejection of faulty sensing elements (Misiewicz et al., 2015). This method enabled both the tyre contact area and the contact pressure distribution to be measured with sensors placed on a smooth sheet of aluminium ( $1.5 \mathrm{~m}$ long $\times 1.5 \mathrm{~m}$ wide $\times 10 \mathrm{~mm}$ thick) located on a 70 $\mathrm{mm}$ thick steel plate. The sensors were covered with a layer of thin plastic film to prevent damage by the tyre treads. The tyres were loaded onto the hard surface and rolled freely straight-ahead at a constant speed of $0.3 \mathrm{~km} \mathrm{~h}^{-1}$ and the contact pressure was logged at a sampling rate of $100 \mathrm{~Hz}$.

The experiments were conducted on a hard surface in the soil bin laboratory, developed by Godwin et al. (1987), which provided controlled conditions for tyre evaluation. The soil tank was $20 \mathrm{~m}$ long, $0.8 \mathrm{~m}$ deep and $1.65 \mathrm{~m}$ wide as shown in Fig. 3. The hard surface experiments required preparation of dense soil conditions in the soil bin onto which three $70 \mathrm{~mm}$ thick steel plates $(2.5 \mathrm{~m}$ long $\times 1.5 \mathrm{~m}$ wide) were placed to provide a non-deformable flat and uniform surface. Then, depending on the method of tyre evaluation, white paper sheets, tyre deflection sensors or pressure sensors were placed on the plates and the tyres were loaded either statically or dynamically. Figure 4 shows the smooth (tread mechanically removed) and treaded Trelleborg T421 Twin Implement 600/55-26.5 166A8 tyres studied. They were used as single free rolling tyres at a range of loads and inflation pressures up to the manufacturer's recommendations for a maximum speed of $10 \mathrm{~km} \mathrm{~h}^{-1}$.

A predictive technique, suggested by Godwin (personal communication, 2007), was investigated to determine the feasibility of using currently available manufacturer's data to estimate tyre carcass stiffness. To develop this possible method, tyre manufacturer's specification graphs were used to estimate tyre stiffness by plotting the maximum load against inflation pressure. This relationship was extrapolated using a linear function in order to provide two selected values:

a. The "negative" inflation pressure at zero load

b. The load at zero inflation pressure

Where:

a. The "negative" inflation pressure at zero load, gives a residual tyre stiffness that 
201 could be an indicator of tyre carcass stiffness. This method is very simple, as it

202 requires only data already published by the tyre manufacturer.

204 b. The load that can be supported by a tyre at zero inflation pressure provides data that can be converted into a pressure applied over the tyre contact area. This method of tyre stiffness estimation requires the tyre contact area to be measured at the recommended load and inflation pressure.

\section{Results and discussion}

\subsection{The footprint area method}

212 The mean contact pressures calculated according to the footprint area were found to

213 be greater than the inflation pressures for both tyres (Figs. 5 and 6). An increase in

214 inflation pressure resulted in a significant rise in the mean contact pressure for both

215 smooth and treaded tyres. The load did not have an effect on the mean contact

216 pressure for either the smooth or treaded implement tyres, while the interaction

217 between the tyre load and inflation pressure was significant at the 95\% confidence

218 level (Misiewicz, 2010).

The difference between the mean contact pressure and tyre inflation pressure for the smooth implement tyre (Fig. 5) was found to vary from $0.1 \times 10^{5} \mathrm{~Pa}$ to $0.5 \times 10^{5} \mathrm{~Pa}$ with a mean value of $0.28 \times 10^{5} \mathrm{~Pa}$. The difference between the mean contact pressure, based on the projected area, and the inflation pressure for the treaded implement tyre was found to vary as a function of tyre inflation pressure with a mean value of $0.41 \times 10^{5} \mathrm{~Pa}$ (Fig. 6a). The difference between the mean contact pressure, according to the tread contact area, and tyre inflation pressure was found to be greater and varied from $2.75 \times 10^{5} \mathrm{~Pa}$ to $5.5 \times 10^{5} \mathrm{~Pa}$ depending on tyre inflation pressure with a mean value of $4.38 \times 10^{5} \mathrm{~Pa}$ (Fig. 6b). The relationships presented in both Figs. 5 and 6, follow the model of Karafiath and Nowatzki (1978), where the $c_{1}$

230 is not equal to 1 .

\subsection{Tyre load - deflection method}

233 Figure 7 shows the data collected for both the smooth and treaded implement tyres. 
234 An increase in tyre load results in an increase in tyre deflection for both tyres and the slope of the load - deflection curve increases as inflation pressure increases. The slopes of the load - deflection curves for the same inflation pressures are approximately the same for the smooth and treaded tyres. However, as the smooth implement tyre was found to deflect more than the treaded tyre the intercepts of the relationships differ. Therefore, it was shown that tyre tread has an effect on tyre vertical deflection; however, it does not have an effect on the slope of the load deflection characteristic; this was expected, as it is the tyre sidewalls that deflect. The slopes of these relationships were plotted against inflation pressure, as shown in Fig. 8 and were found to be linear (coefficient of determination $\left(R^{2}\right)=0.9957$ and 0.9853, respectively). Extrapolation of the trends to the intercept of the inflation pressure axis gave predicted carcass stiffness of $0.83 \times 10^{5} \mathrm{~Pa}$ for both the smooth and treaded implement tyres.

\subsection{The pressure mapping method}

249 Figures 9 and 10 show the mean and maximum contact pressure vs. inflation 250 pressure respectively for both the smooth and the treaded tyre obtained using the pressure mat. The data confirmed that as inflation pressure increases there is an increase in both the mean and maximum contact pressure for both smooth and treaded tyres. Both the mean and maximum contact pressures were found to be higher than the tyre inflation pressure over the range studied. As expected the effect of the tyre tread significantly increased both the mean and maximum contact pressures at the $95 \%$ confidence level. The linear regression analyses confirmed that both tyre load and inflation pressure had significant effects on the mean and maximum contact pressure of the smooth tyre. For the treaded tyre, only the inflation pressure had an influence on the resulting contact pressures. Statistical ' $t$ ' tests showed that the contact pressure did not increase at the same rate as tyre inflation pressure, therefore, the effect of inflation pressure on the contact pressure is affected by the $c_{1}$ (not equal to 1), also in agreement with Karafiath and Nowatzki (1978).

The difference between the mean contact pressure and inflation pressure, considered as mean carcass stiffness, for the smooth tyre varied between $0.3 \times 10^{5}$ 
$\mathrm{Pa}$ and $0.7 \times 10^{5} \mathrm{~Pa}$ and the maximum carcass stiffness varied between $3 \times 10^{5} \mathrm{~Pa}$ and $5 \times 10^{5} \mathrm{~Pa}$. The overall mean values of mean and maximum carcass stiffness of the smooth implement tyre were found to be $0.44 \times 10^{5} \mathrm{~Pa}$ and $3.81 \times 10^{5} \mathrm{~Pa}$, respectively. For the rated loads and inflation pressures, the means of the mean and maximum carcass stiffness were $0.54 \times 10^{5} \mathrm{~Pa}$ and $4.46 \times 10^{5} \mathrm{~Pa}$, respectively.

The carcass stiffness of the treaded implement tyre was found to be significantly greater than the carcass stiffness of the smooth tyre. The mean values were found to vary between $2.0 \times 10^{5}$ and $3.2 \times 10^{5} \mathrm{~Pa}$ and the maximum carcass stiffness varied between $5.9 \times 10^{5}$ and $8.4 \times 10^{5} \mathrm{~Pa}$. The overall mean values of mean and maximum carcass stiffness of the treaded implement tyre tested were equal to $2.51 \mathrm{X}$ $10^{5} \mathrm{~Pa}$ and $7.16 \times 10^{5} \mathrm{~Pa}$, respectively. For the rated loads and inflation pressures, the means of the mean and maximum carcass stiffness were $2.53 \times 10^{5} \mathrm{~Pa}$ and 7.25 x $10^{5} \mathrm{~Pa}$, respectively.

\subsection{Tyre manufacturer's specification method}

The load vs. inflation pressure data for the implement tyre from the tyre manufacture's specification for a range of loading cycles and speeds was considered by extrapolating the relationships using a linear regression analyses. The relationships were found to be highly linear with the $R^{2}>0.999$ (Misiewicz, 2010). Extrapolating these relationships produces a range of points on the negative inflation pressure axis that tend to converge. Using the inflation pressure at zero load for a free rolling implement tyre at a speed of $10 \mathrm{~km} \mathrm{~h}^{-1}$, as shown in Fig. 11 as an example of the implied carcass stiffness and as the closest speed to the speed used in the experiment, the results were found to be $0.79 \times 10^{5} \mathrm{~Pa}$.

The carcass stiffness was also estimated based on the tyre load which can be carried by a non-inflated tyre (Fig. 11). It was observed that tyres maintain a near constant contact area, when they are loaded with the recommended load for a given inflation pressure, according to tyre manufacture specifications (Misiewicz, 2010). Therefore, only one contact area experimental test for a tyre is required or, in the future, it could be provided in the tyre manufacturer's specification data. The contact areas, required in order to convert the load that the tyres are able to carry with no pressure, were determined using the pressure mapping system. The carcass 
stiffnesses of the free rolling implement tyre at $10 \mathrm{~km} \mathrm{~h}^{-1}$ were found to be:

- for the smooth tyre: $0.65 \times 10^{5} \mathrm{~Pa}$ (mean contact area $0.26 \mathrm{~m}^{2}$ )

- for treaded tyre: $2.12 \times 10^{5} \mathrm{~Pa}$ (mean tread contact area $0.08 \mathrm{~m}^{2}$ )

\subsection{Comparison of results}

Table1 and Fig. 12 compare the results obtained for different methods of carcass stiffness determination. The carcass stiffness values provided by the footprint area method were considerably lower than the results obtained using the pressure difference method using the pressure mapping system. The results were approximately $30-40 \%$ lower than the tyre carcass stiffness obtained by the pressure mapping method, so they should not be used for estimating mean contact pressure on a hard surface. This indicates that the contact areas provided by the footprint area method include areas where the tyres have contact with the surface but transfer little or no load, which leads to an underestimate of the mean contact pressure. The methods based on tyre load - deflection and tyre manufacturer specification data based on the inflation pressure at zero load, produced estimates of the mean tyre carcass stiffness that are closer to those measured using the pressure mapping method for the smooth tyre. The estimation of the tyre carcass stiffness according to the theoretical load that the tyre is able to sustain at zero inflation pressure, gave the closest agreement with the mean carcass stiffness of both the smooth and treaded tyres studied, this was found to lie within $\pm 20 \%$ of that determined using the pressure mapping system. Hence, the method based on tyre manufacturer data using the load at zero inflation pressure is recommended as a simple indicator of the mean tyre carcass stiffness in the absence of equipment to record actual contact pressure. To make this method easier the intercept data for the zero load and the rated contact area should be included in the tyre manufacturer's specification.

\section{Conclusions}

Using the pressure mapping method, where the mean and maximum contact pressures of the tyre footprint were determined, allowed the following methods of carcass stiffness estimation to be evaluated:

i. The footprint area method to estimate the size of the contact patch and 
hence the mean contact pressure,

ii. Tyre load - deflection method,

iii. Tyre manufacturer's specification method.

337 Carcass stiffness values obtained using the footprint area method were significantly

338 less $(30-40 \%)$ than the tyre carcass stiffness values obtained by using the pressure mapping method. The methods based on the tyre load - deflection and tyre manufacturer's specification based on the inflation pressure at zero load gave a better estimates of the mean tyre carcass stiffness of the smooth tyre. The method based on the tyre manufacturer's specification data, where the estimate of the tyre carcass stiffness was according to the theoretical load that the tyre is able to sustain at zero inflation pressure, gave the best agreement with the mean carcass stiffness of both the smooth and treaded tyres which was found to be within $\pm 20 \%$ of that recorded using the pressure mapping method.

The pressure mapping method can be used to determine the maximum carcass stiffness, which was found to be approximately 3 times the mean carcass stiffness of the treaded tyre.

The tyre tread of the Trelleborg 600/55-26.5 tyre has a significant effect on the contact area; mean and maximum contact pressure and the resulting carcass stiffness on a hard surface.

In order to provide practical assistance in the selection of tyres with the lowest mean contact pressure, the carcass stiffness estimated from the tyre manufacturer specification data should be used. To make this method easier the intercept data for the zero load and the rated contact area should be included in the tyre manufacturer's specification.

\section{References}

363 Ansorge, D., \& Godwin, R.J. (2007). The effect of tyres and a rubber track at high 364 axle loads on soil compaction, Part 1: Single axle-studies. Biosystems Engineering, $36598(1), 115-126$.

366 Bekker, M.G. (1956). Theory of land locomotion: the mechanics of vehicle mobility.

367 The University of Michigan Press, USA. 
Chamen, W.C.T. (2011). The mechanisation, economics and agronomic effects of field traffic management on cropping systems. PhD thesis, Cranfield University,

370 Cranfield, UK.

371 Chancellor, W.J. (1976). Compaction of soil by agricultural equipment. Bulletin 1881.

372 Div. Agric. Sci. University of California, Davis, USA.

373 Godwin, R.J., Magalhaes, P.S.G., Miller, S.M, \& Fry, R.K. (1987). Instrumentation to 374 study the force systems and vertical dynamic behaviour of soil-engaging implements. 375 Journal of Agricultural Engineering Research, 36, 301 - 310.

376 Koch, H. J., Heuer, H., Tomanova, O., \& Marlander, B. (2008). Cumulative effect of 377 annually repeated passes of heavy agricultural machinery on soil structural 378 properties and sugar beet yield under two tillage systems. Soil \& Tillage Research, $379101,69-77$.

380. Horn, R., Fleige, H., Peth, S., \& Peng, X. (2006). Soil management for sustainability, 381 Advances in GeoEcology. The 17th Triennial International Soil Tillage Research 382 Conference, CATENA VERLAG GMBH, Kiel, Germany, 28 August - 3 September 3832006.

384 Karafiath, L.L., \& Nowatzki, E.A. (1978). Soil mechanics for off-road vehicle 385 engineering. $1^{\text {st }}$ edition, Trans Tech Publications, Germany.

386 Keller, T. and Lamandé, M. (2010). Challenges in the development of analytical soil 387 compaction models. Soil and Tillage Research, 111, $54-64$.

388 Misiewicz P.A., Blackburn, K., Richards, T.E., Brighton, J.L., \& Godwin, R.J. (2015).

389 The evaluation and calibration of pressure mapping system for the measurements of

390 the pressure distribution. Biosystems Engineering, 130, $81-91$.

391 Misiewicz, P.A. (2010). The evaluation of the soil pressure distribution and carcass stiffness resulting from pneumatic agricultural tyres. PhD Thesis, Cranfield

393 University, Cranfield, UK.

394 Plackett, C.W. (1986). Instrumentation to measure the deformation and contact 395 stress of pneumatic tyres operating in soft soil. Divisional Note DN 1322. National 396 Institute of Agricultural Engineering, Silsoe, England.

397 Plackett, C.W. (1984). The ground pressure of some agricultural tyres at low load 398 and with zero sinkage. Journal of Agricultural Engineering Research, 29, 159 - 166.

399 Plackett, C.W. (1983). Hard surface contact area measurement for agricultural tyres. 400 Divisional Note DN 1200. National Institute of Agricultural Engineering, Silsoe,

401 England.

402 Plackett, C.W., Clemens K., Dwyer, M. J., \& Febo, P. (1987). The ground pressure of 403 agricultural tyres. AFRC Institute of Engineering Research, Report No.49. 
404 Schjonning, P., Lamande, M., Togersen, F.A., Arvidsson, J., \& Keller, T. (2008).

405 Modelling effects of tyre inflation pressure on the stress distribution near the soil 406 tyre interface. Biosystems Engineering, 99, 119 - 133.

407 Soane, B.D, Blackwell, P.S., Dickson, J.W., \& Painter, D.J. (1981). Compaction by 408 agricultural vehicles: a review, I. Soil and wheel characteristics. Soil Tillage

409 Research, 1, $207-237$.

410 Söhne, W.H. (1958). Fundamentals of pressure distribution and soil compaction

411 under tractor tyres. Agricultural Engineering, 39, 276 - 281, 290.

412 Trautner, A. (2003). On soil behaviour during field traffic. PhD thesis, Swedish

413 University of Agricultural Sciences, Uppsala.

414 VandenBerg, G.E., \& Gill, W.R. (1962). Pressure distribution between a smooth tyre 415 and the soil. Transactions of ASAE, 5, 2, $105-107$.

416

417

418

419

420

421

422 


\section{Figures:}

424 Fig. 1. Load vs. deflection curves for a tyre at a range of inflation pressures (redrawn 425 from Plackett, 1983)

426 Fig. 2. Carcass stiffness estimated from the inflation pressure vs. slope of load 427 deflection curves for three tyres (redrawn from Plackett, 1983)

428 Fig. 3. Soil bin laboratory (a: soil surface preparation, b: pressure mapping system 429 placed on the steel plates)

430 Fig. 4. Smooth (a) and treaded (b) Trelleborg T421 Twin Implement 600/55-26.5 431 tyres

432 Fig. 5. Mean contact pressure vs. inflation pressure for the smooth 600/55-26.5 433 implement tyre from the footprint area method (*the single marker centred within 434 each circle indicates a data point for a rated combination of load and inflation 435 pressure)

436 Fig. 6. Mean and maximum contact pressure vs. inflation pressure for the 600/55-

43726.5 treaded implement tyre from the footprint area method ( ${ }^{*}$ the single marker 438 centred within each circle indicates a data point for a rated combination of load and 439 inflation pressure)

440 Fig. 7. Load vs. deflection curves - smooth (a) and treaded (b) 600/55-26.5

441 implement tyre (*the single marker centred within each circle indicates a data point 442 for a rated combination of load and inflation pressure)

443 Fig. 8. Inflation pressure vs. slope of load - deflection curve - smooth (left) and 444 treaded (right) 600/55-26.5 implement tyre

445 Fig. 9. Mean and maximum contact pressures vs. tyre inflation pressure for the 446 smooth 600/55-26.5 implement tyre for a range of safe working loads based on the 447 pressure mapping system ( ${ }^{*}$ the single marker centred within each circle indicates a 448 data point for a rated combination of load and inflation pressure)

449 Fig. 10. Mean and maximum contact pressures vs. tyre inflation pressure for the 450 treaded 600/55-26.5 implement tyre for a range of safe working loads based on the 451 pressure mapping system ( ${ }^{*}$ the single marker centred within each circle indicates a 452 data point for a rated combination of load and inflation pressure)

453 Fig. 11. Tyre manufacturer's specification data showing the inflation pressure vs. 454 load with a linear regression function for the 600/55-26.5 implement tyre (free rolling 455 at $10 \mathrm{~km} \mathrm{~h}^{-1}$ speed)

456 Fig. 12. Comparison of the mean estimated tyre carcass stiffness values with 
459 Tables:

460 Table 1. Comparison of mean carcass stiffness values of the smooth and treaded 461 Trelleborg T421 Twin Implement 600/55-26.5 tyres 


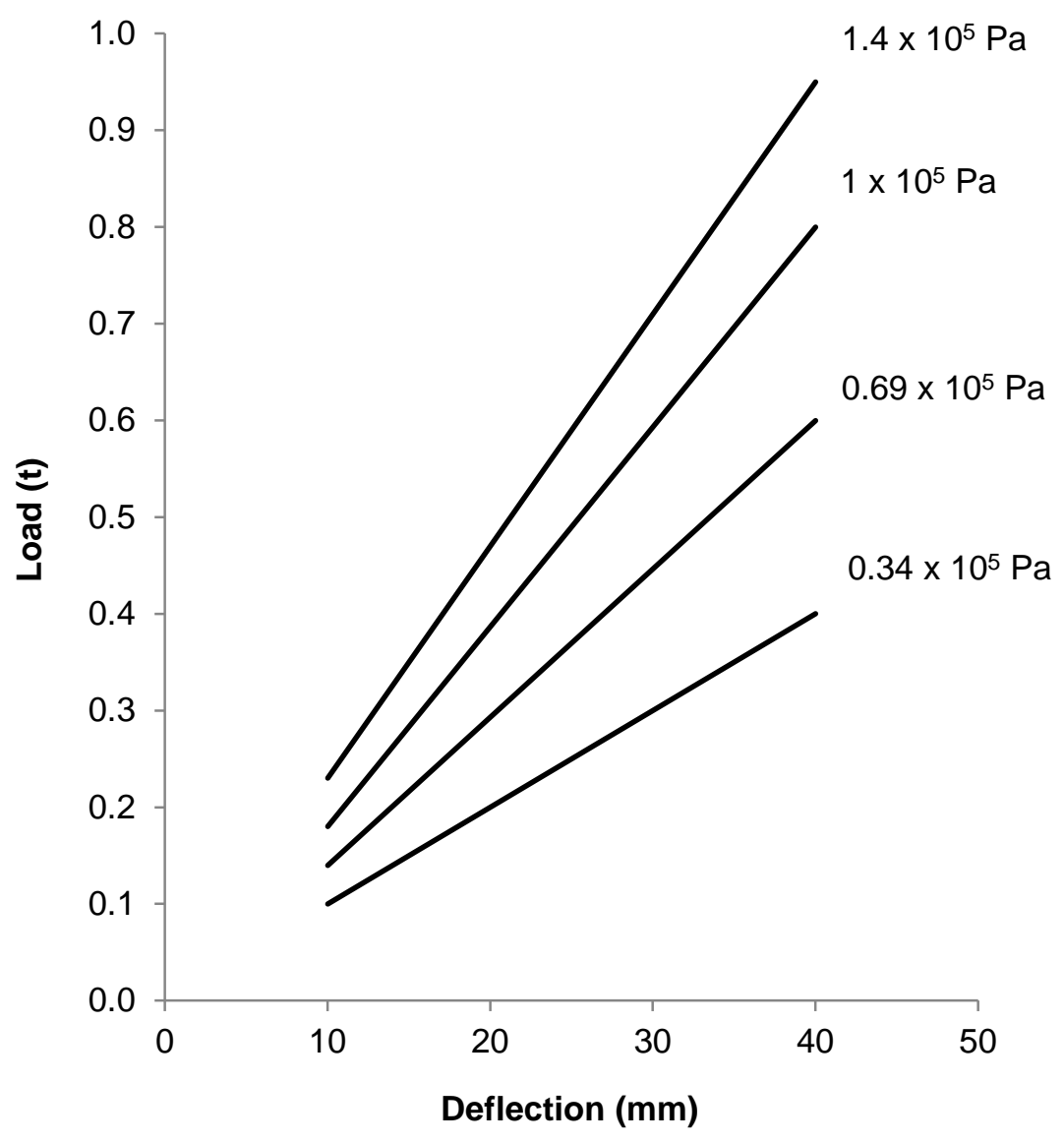

462

463 Fig. 1. Load vs. deflection curves for a tyre at a range of inflation pressures (redrawn 464 from Plackett, 1983) 


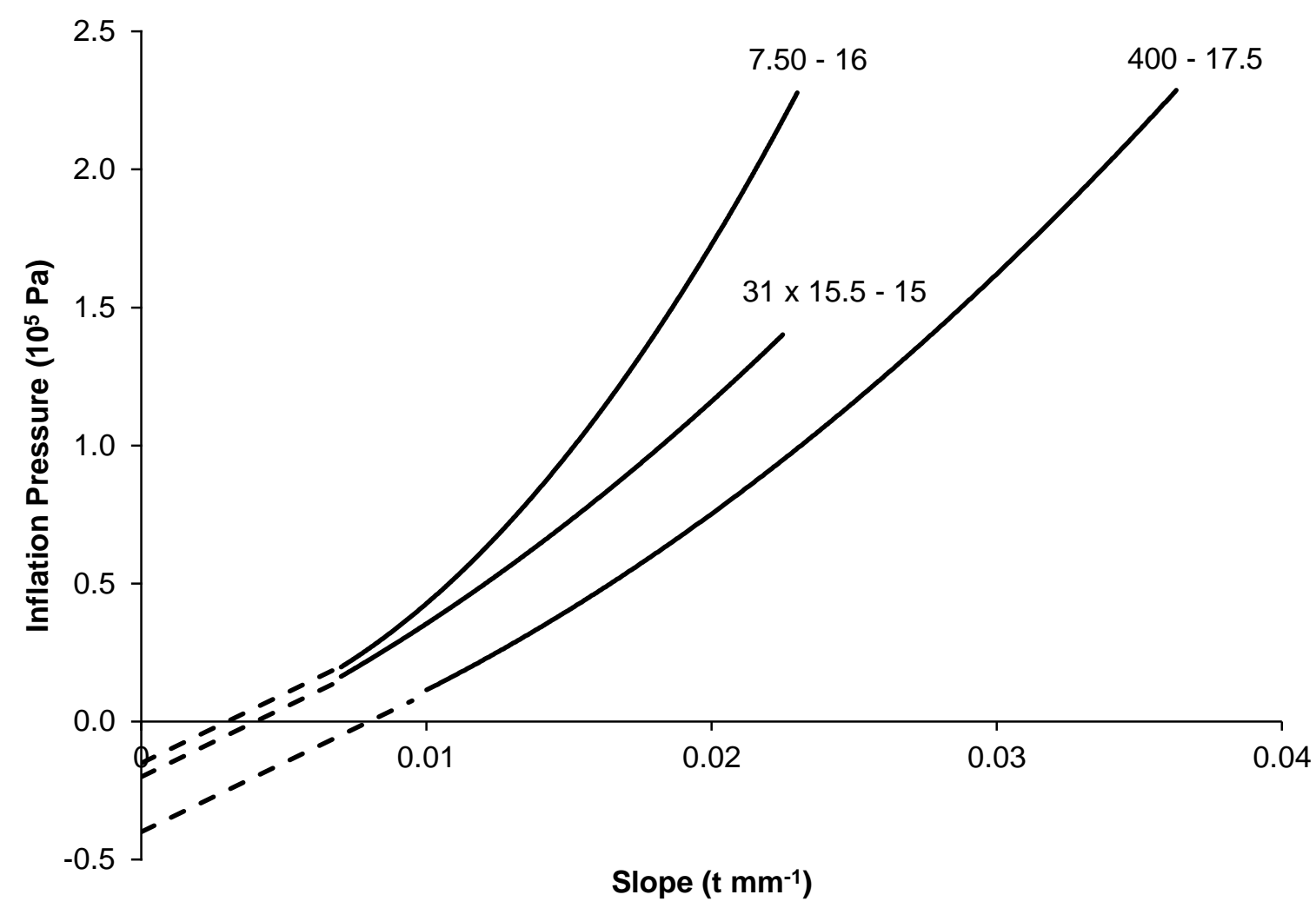

467 Fig. 2. Carcass stiffness estimation from the inflation pressure vs. slope of load 468 deflection curves for three tyres (redrawn from Plackett, 1983) 
469
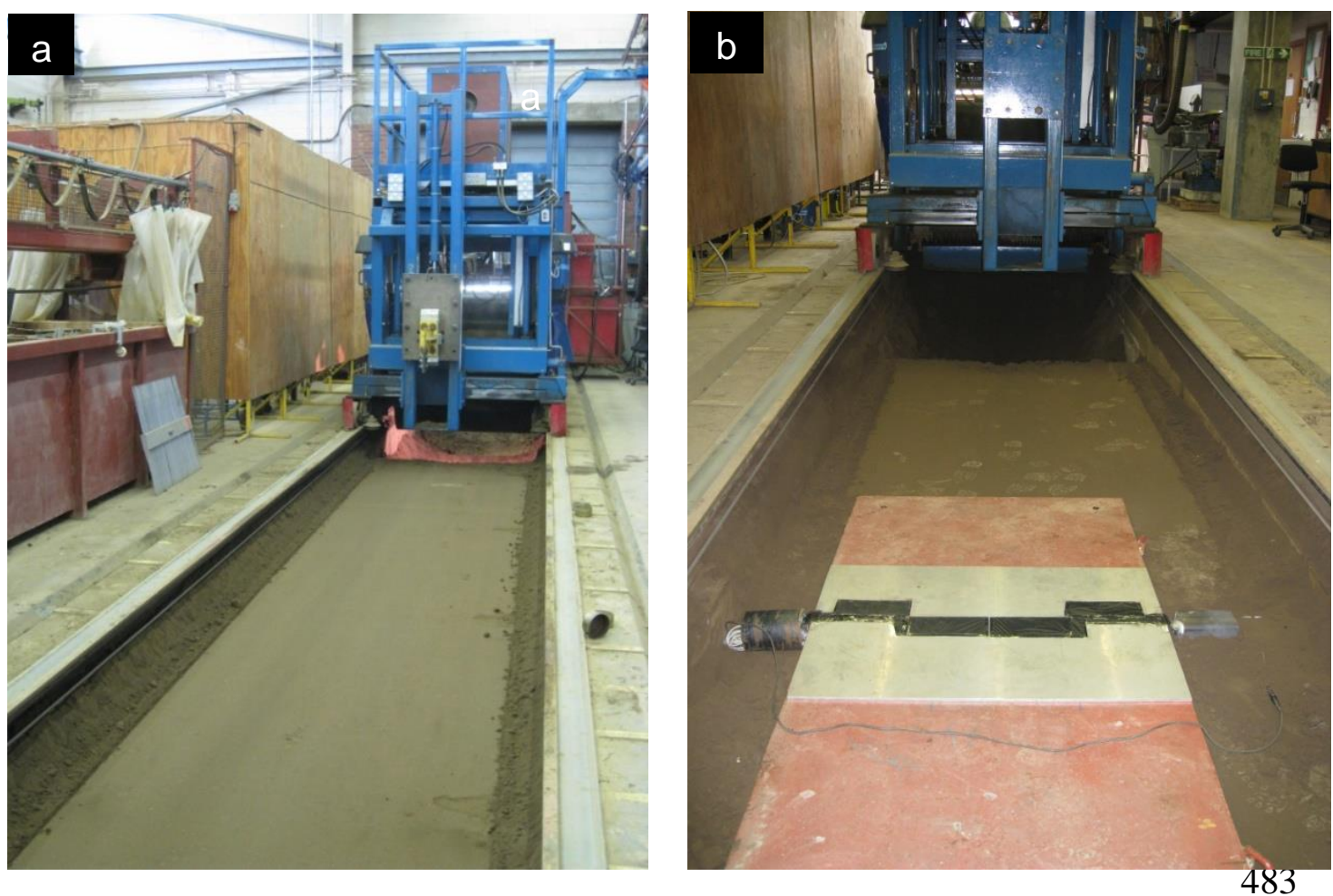

484 Fig. 3. Soil bin laboratory (a: soil surface preparation, b: pressure mapping system 485 placed on the steel plates) 
486

487

488

489

490

491

492

493

494
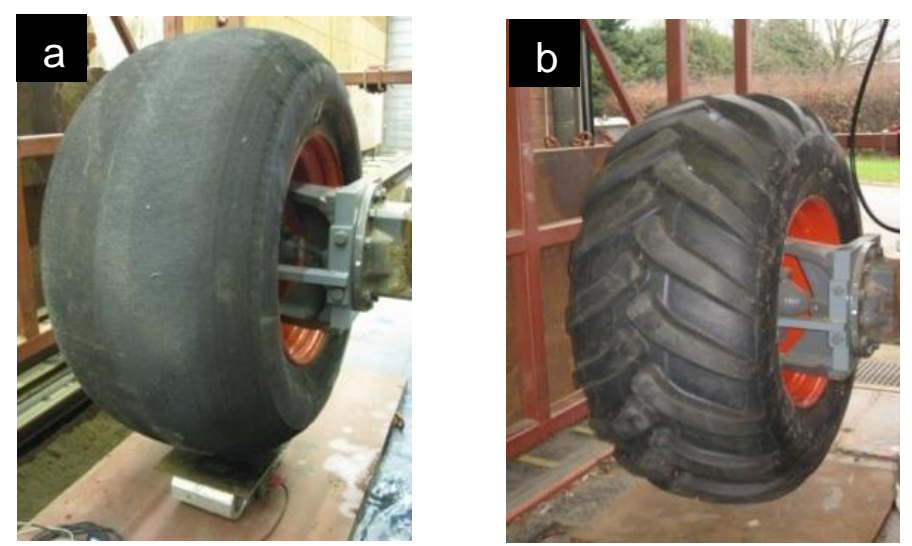

495 Fig. 4. Smooth (a) and treaded (b) Trelleborg T421 Twin Implement 600/55-26.5 496 tyres

497

498

499

500

501

502

503

504

505

506

507

508

509

510 


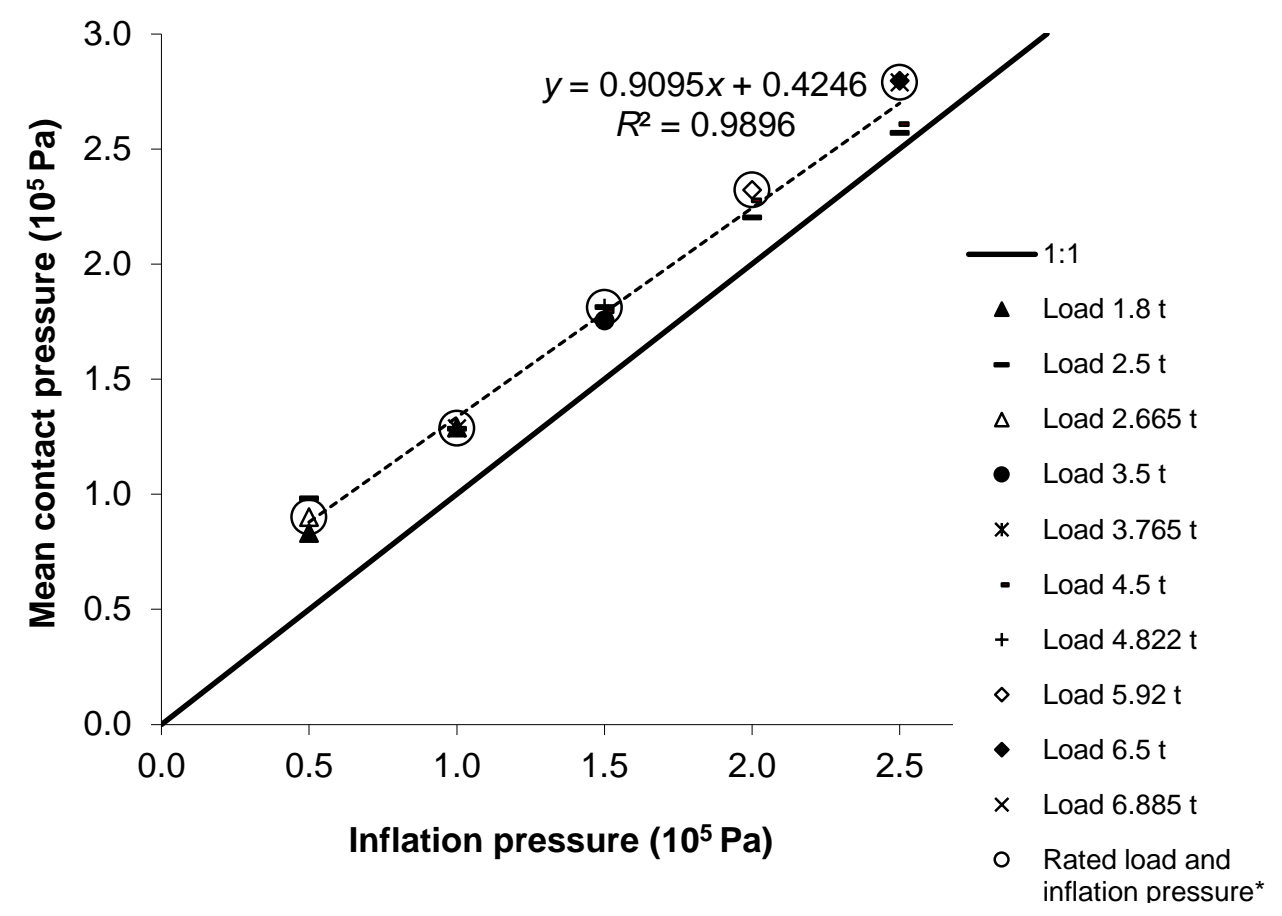

Fig. 5. Mean contact pressure vs. inflation pressure for the smooth 600/55-26.5

513 implement tyre from the footprint area method (*the single marker centred within

514 each circle indicates a data point for a rated combination of load and inflation

515 pressure) 


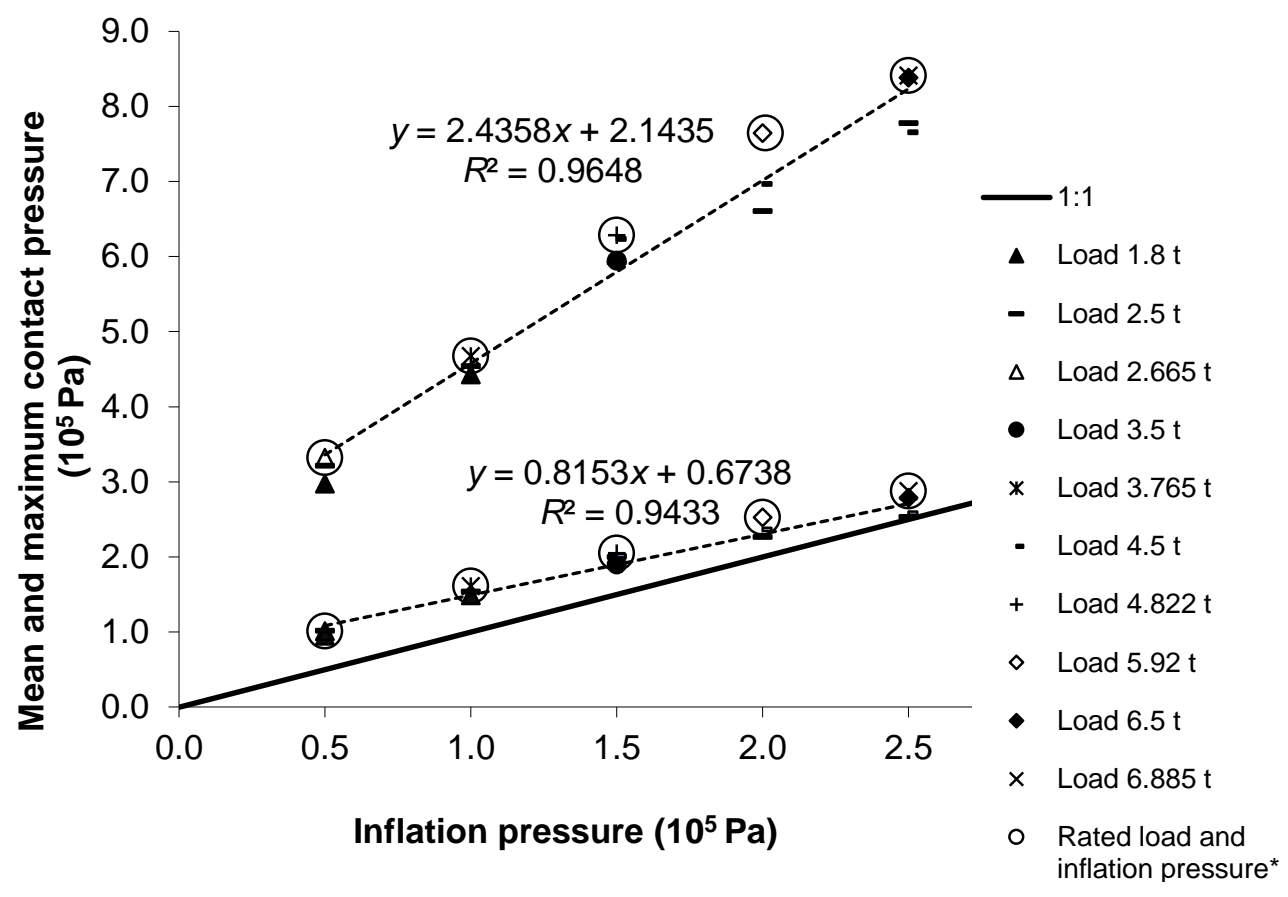

Fig. 6. Mean and maximum contact pressure vs. inflation pressure for the 600/55-

51826.5 treaded implement tyre from the footprint area method ( ${ }^{*}$ the single marker

519 centred within each circle indicates a data point for a rated combination of load and 520 inflation pressure)

521

522

523

524

525

526

527

528

529 
530

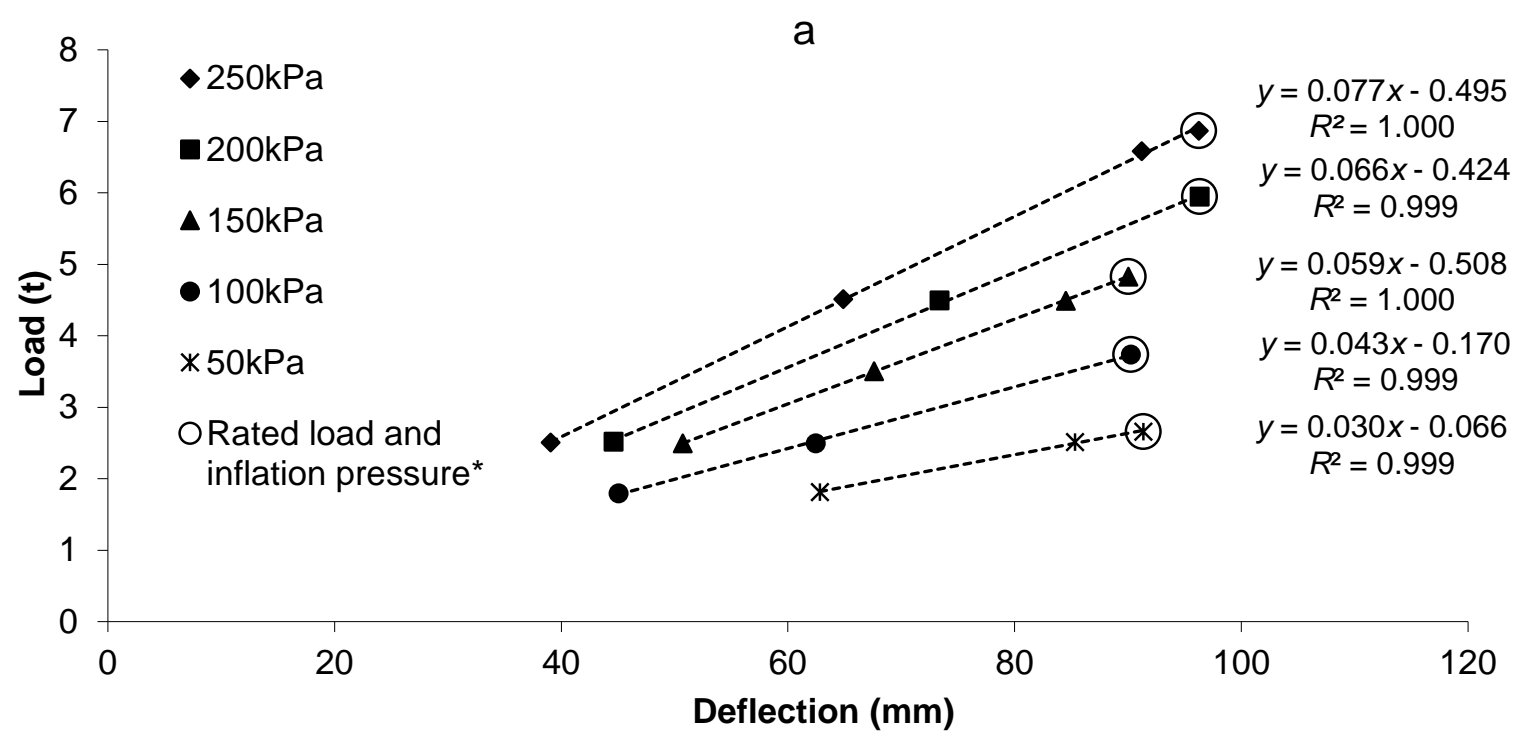

531

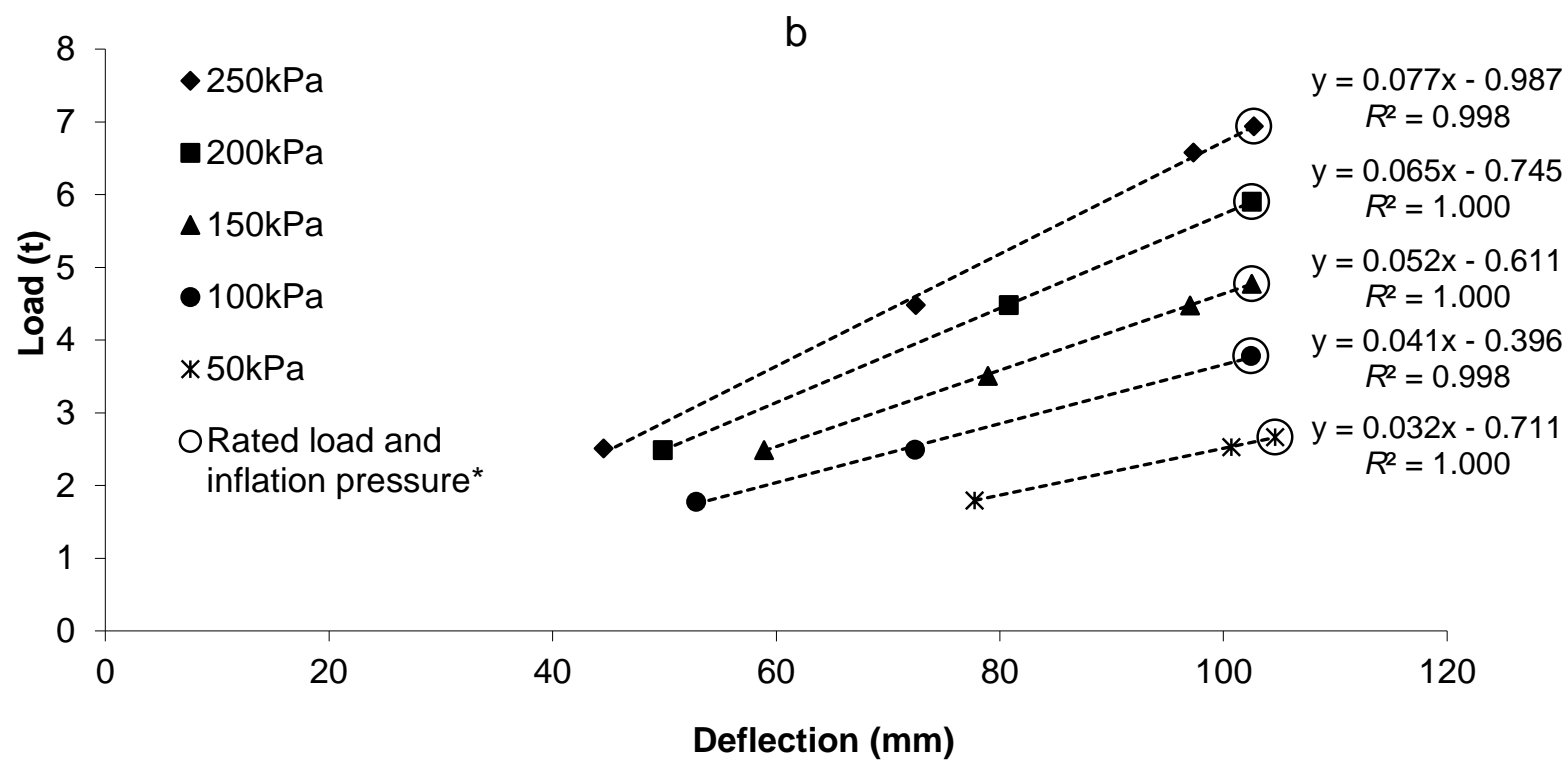

532

533 Fig. 7. Load vs. deflection curves - smooth (a) and treaded (b) 600/55-26.5

534 implement tyre (*the single marker centred within each circle indicates a data point

535 for a rated combination of load and inflation pressure) 
536
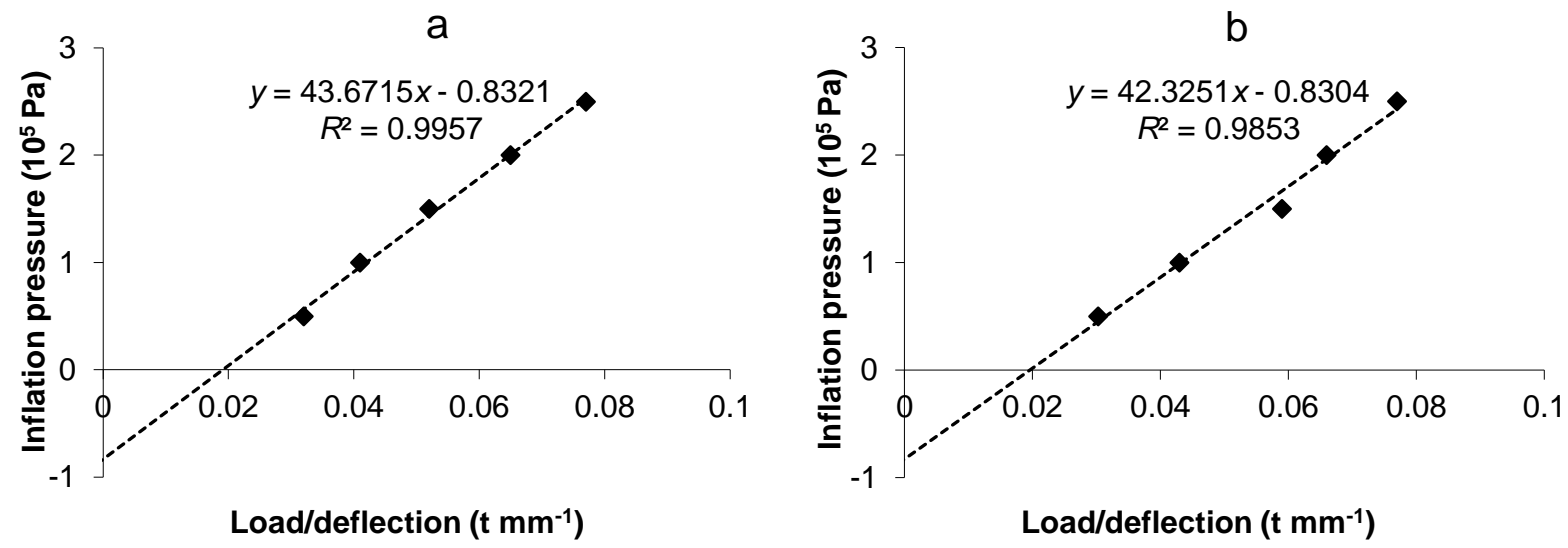

537 Fig. 8. Inflation pressure vs. slope of load - deflection curve - smooth (a) and 538 treaded (b) 600/55-26.5 implement tyre 


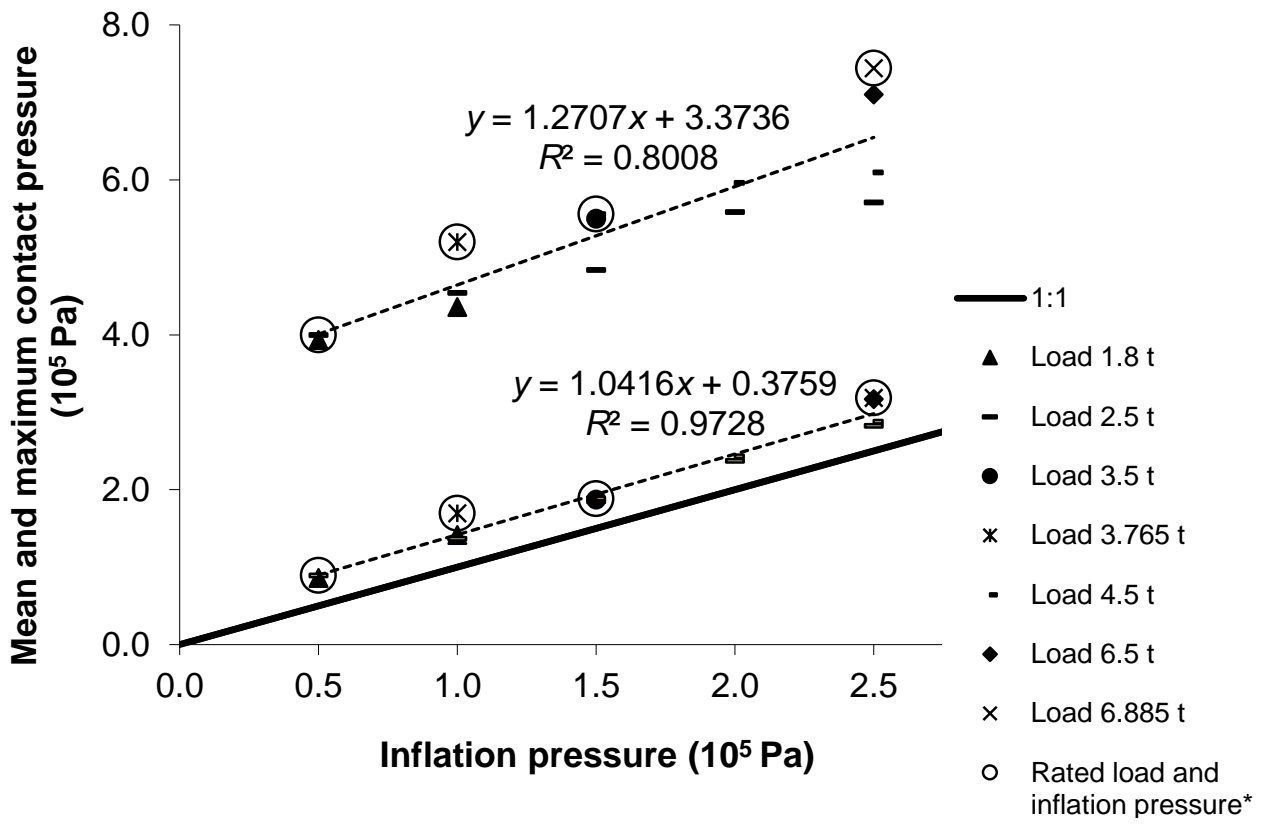

Fig. 9. Mean and maximum contact pressures vs. tyre inflation pressure for the

541 smooth 600/55-26.5 implement tyre for a range of safe working loads based on the

542 pressure mapping system (*the single marker centred within each circle indicates a

543 data point for a rated combination of load and inflation pressure)

544

545

546

547

548

549

550

551

552

553

554

555

556

557

558

559 


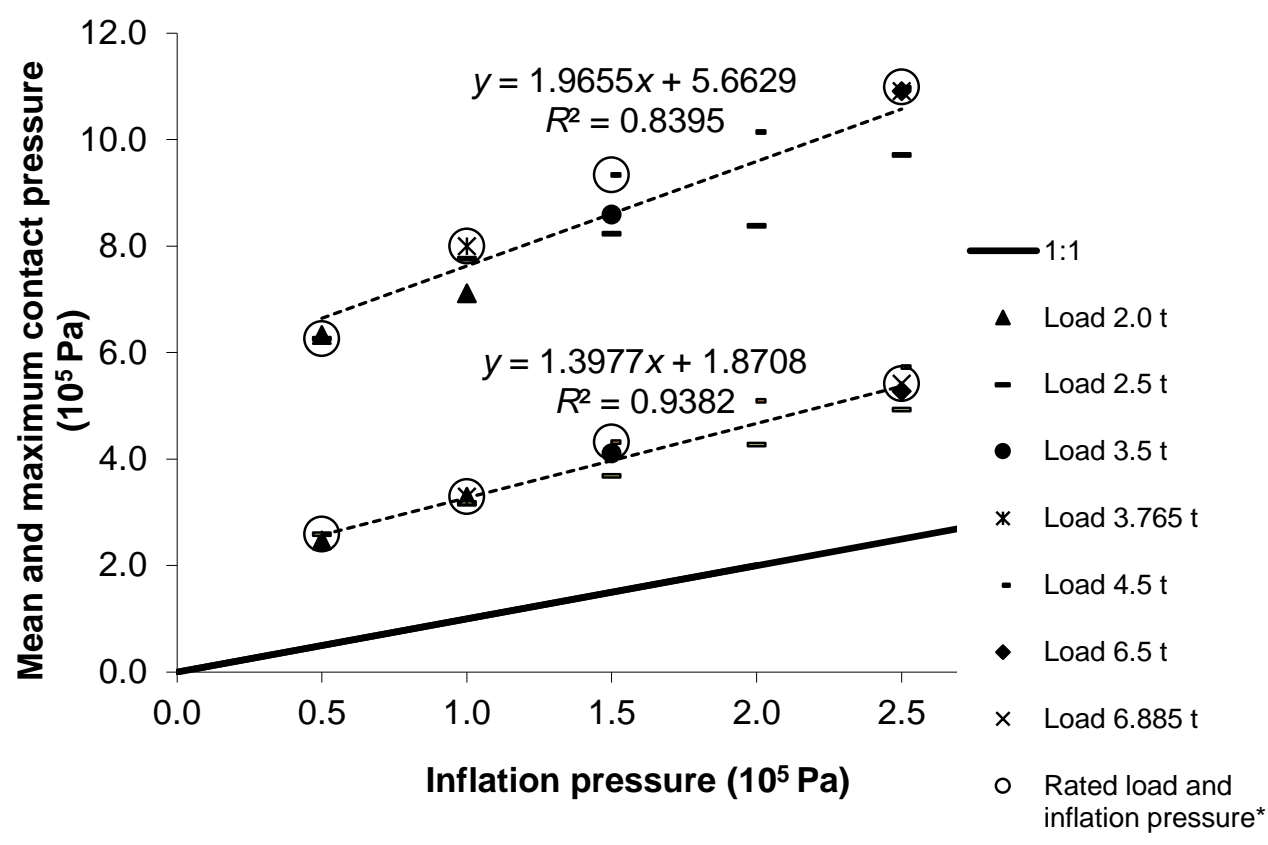

560

Fig. 10. Mean and maximum contact pressures vs. tyre inflation pressure for the

562 treaded 600/55-26.5 implement tyre for a range of safe working loads based on the

563 pressure mapping system (*the single marker centred within each circle indicates a

564 data point for a rated combination of load and inflation pressure)

565

566

567

568

569

570

571

572

573

574

575 


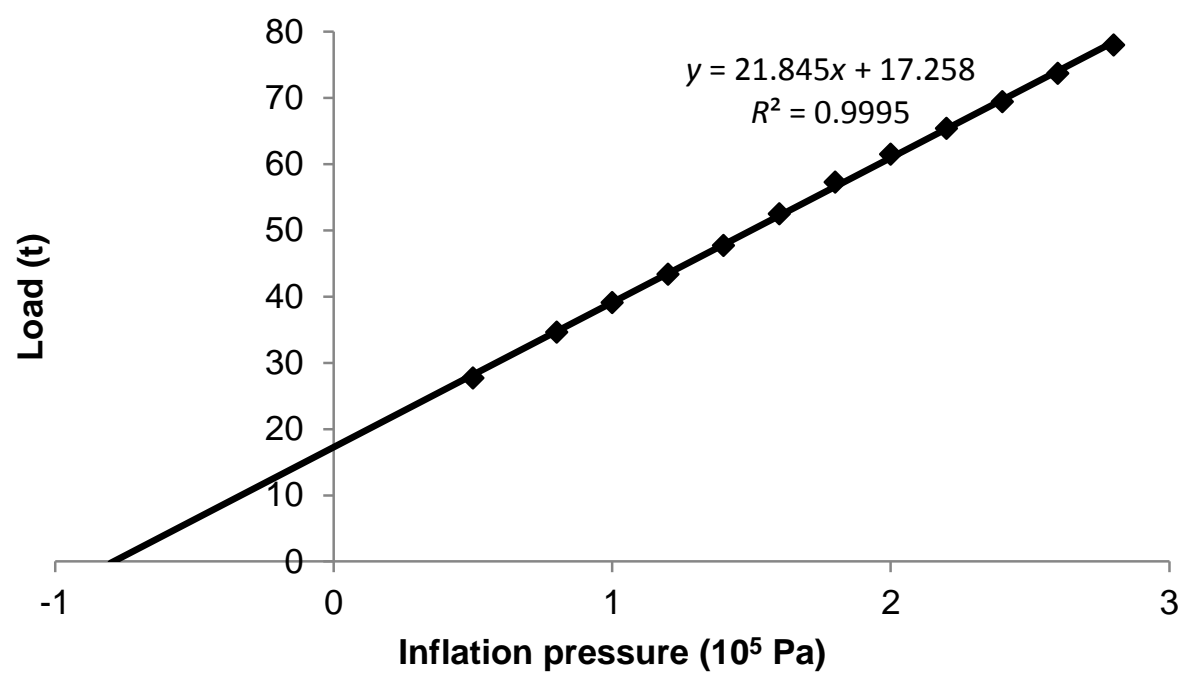

576

577 Fig. 11. Tyre manufacturer's specification data showing the inflation pressure vs.

578 load with a linear regression function for the 600/55-26.5 implement tyre (free rolling 579 at $10 \mathrm{~km} \mathrm{~h}^{-1}$ speed) 
580

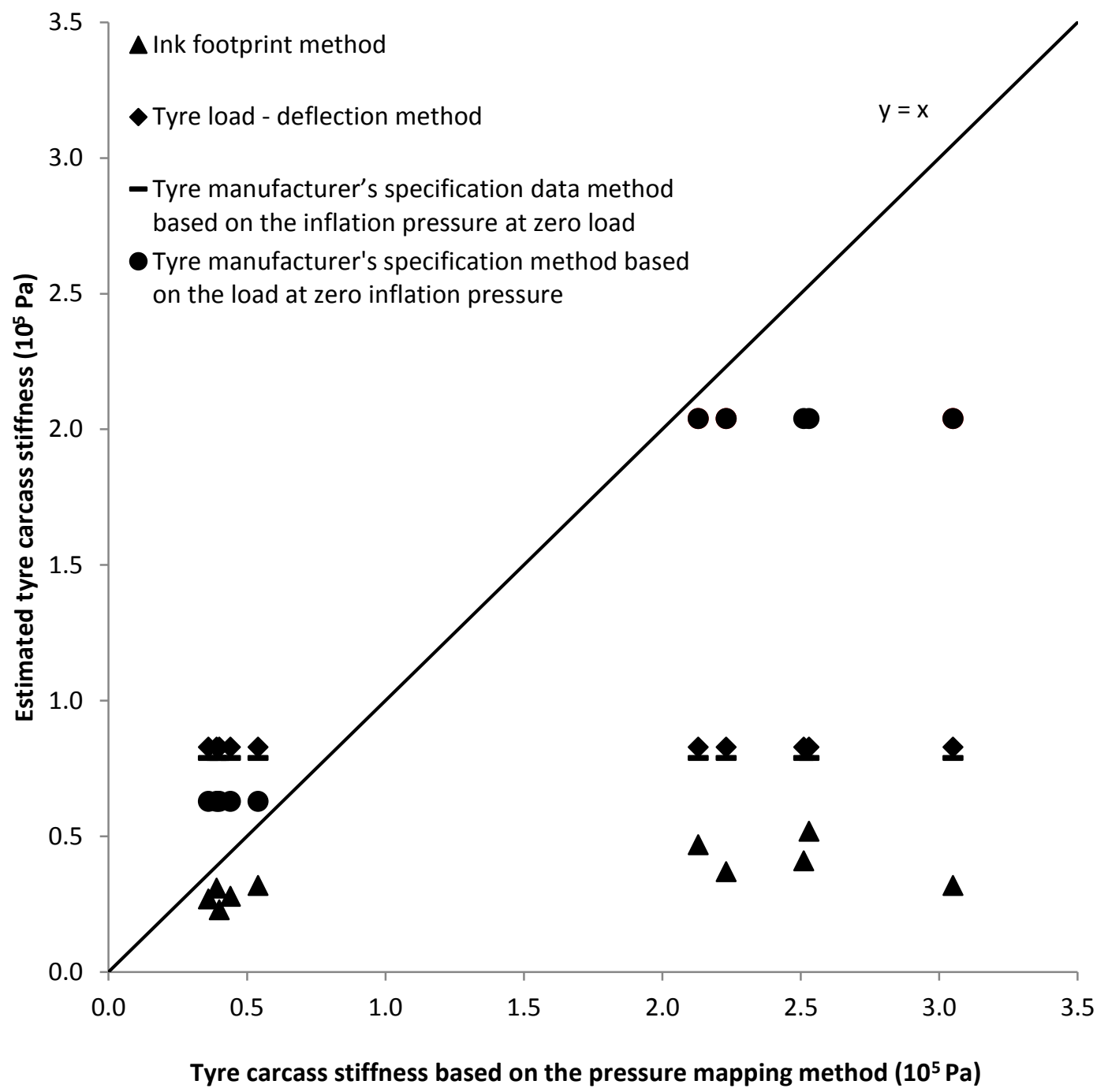

581

582 Fig. 12. Comparison of the mean estimated tyre carcass stiffness values with

583 absolute measured values for the Trelleborg T421 Twin Implement 600/55-26.5 tyres 
584 Table 1. Comparison of mean carcass stiffness values of the smooth and treaded Trelleborg T421 Twin Implement 600/55-26.5 585 tyres

\begin{tabular}{|c|c|c|c|c|c|c|c|}
\hline \multirow[b]{2}{*}{ Tyre } & \multicolumn{2}{|c|}{ Pressure mapping method } & \multicolumn{2}{|c|}{ Footprint area method } & \multirow{2}{*}{$\begin{array}{c}\text { Load - deflection } \\
\text { method } \\
P_{C S} \\
\left(10^{5} \mathrm{~Pa}\right)\end{array}$} & \multicolumn{2}{|c|}{$\begin{array}{c}\text { Tyre manufacturer's specification method } \\
\text { at } 10 \mathrm{~km} \mathrm{~h}^{-1}\end{array}$} \\
\hline & $\begin{array}{c}\text { Overall mean } \\
P_{C S} \\
\left(10^{5} \mathrm{~Pa}\right)\end{array}$ & $\begin{array}{c}P_{C S} \\
\text { at rated load } \\
\text { and pressure } \\
\left(10^{5} \mathrm{~Pa}\right)\end{array}$ & $\begin{array}{c}\text { Overall mean } \\
P_{C S} \\
\left(10^{5} \mathrm{~Pa}\right)\end{array}$ & $\begin{array}{c}P_{C S} \\
\text { at rated load } \\
\text { and pressure } \\
\left(10^{5} \mathrm{~Pa}\right)\end{array}$ & & $\begin{array}{c}P_{C S} \\
\text { An inflation pressure } \\
\text { at zero load } \\
\left(10^{5} \mathrm{~Pa}\right)\end{array}$ & $\begin{array}{c}P_{C S} \\
\text { A load at zero } \\
\text { inflation pressure } \\
\left(10^{5} \mathrm{~Pa}\right)\end{array}$ \\
\hline $\begin{array}{c}\text { 600/55-26.5 } \\
\text { smooth } \\
\text { implement tyre }\end{array}$ & 0.44 & 0.54 & 0.28 & 0.32 & 0.83 & 0.79 & 0.65 \\
\hline $\begin{array}{c}600 / 55-26.5 \\
\text { treaded } \\
\text { implement tyre }\end{array}$ & 2.51 & 2.53 & 0.41 & 0.52 & 0.83 & 0.79 & 2.12 \\
\hline
\end{tabular}

